\title{
Volumetric Properties of Aqueous Solutions of Ethylene Glycols in the Temperature Range of 293.15-318.15 K
}

\author{
Omer El-Amin Ahmed Adam, ${ }^{1,2}$ Ammar Hani Al-Dujaili, ${ }^{1}$ and Akl M. Awwad ${ }^{3}$ \\ ${ }^{1}$ Department of Chemistry, College of Education for Pure science/Ibn Al-Haitham, University of Baghdad, P.O. Box 4150, \\ Baghdad 10001, Iraq \\ ${ }^{2}$ Chemistry Department, University of Kassala, P.O. Box 266, Kassala 31111, Sudan \\ ${ }^{3}$ Industrial Chemistry Centre, Royal Scientific Society, P.O. Box 1438, Al-Jubaiha 11941, Amman, Jordan
}

Correspondence should be addressed to Omer El-Amin Ahmed Adam; omaramin1967@gmail.com

Received 18 November 2013; Accepted 24 December 2013; Published 10 February 2014

Academic Editors: M. Lewis and R. D. Parra

Copyright (C) 2014 Omer El-Amin Ahmed Adam et al. This is an open access article distributed under the Creative Commons Attribution License, which permits unrestricted use, distribution, and reproduction in any medium, provided the original work is properly cited.

\begin{abstract}
Densities of aqueous solutions of Ethylene glycol (EG), diethylene glycol (DEG), and triethylene glycol (TEG) were measured at temperatures from 293.15 to $318.15 \mathrm{~K}$ and molalities ranging from 0.0488 to $0.5288 \mathrm{~mol} \cdot \mathrm{kg}^{-1}$. Volumes of all investigated solutions at a definite temperature were linearly dependent on the solute molality; from this dependence the partial molar volumes at infinite dilution were determined for all solutes. It was found that the partial molar volumes at infinite dilution $\left(\bar{V}_{2,0}\right)$ were concentration independent and slightly increase with increasing temperature. The partial molar volumes at infinite dilution $\left(\bar{V}_{2,0}\right)$ or the limiting apparent molar volumes of ethylene glycols were fitted to a linear equation with the number of oxyethylene groups $(n)$ in the solute molecule. From this equation a constant contribution of the terminal $(\mathrm{OH})$ and the $\left(\mathrm{CH}_{2} \mathrm{CH}_{2} \mathrm{O}\right)$ groups to the volumetric properties was obtained. The thermal expansion coefficient $\left(\alpha_{1,2}\right)$ for all investigated solutions was calculated at temperatures from 293.15 to $318.15 \mathrm{~K}$. The thermal expansion coefficients for all solutes increase with increasing temperature and molality. Values of $\left(\alpha_{1,2}\right)$ were higher than the value of the thermal expansion coefficient of the pure water.
\end{abstract}

\section{Introduction}

Mixing effects for thousands of chemical compounds and their mixtures used in industry are rather difficult to be known; hence, knowledge of thermodynamic properties such as densities, as well as excess molar volumes, $V^{E}$, partial molar volumes, and apparent molar volumes of organic mixtures at various temperatures, is of great importance. Solvation of a solute in certain solvent and different types of interactions, solute-solvent and solvent-solvent interactions, are of great importance in physical chemistry [1].

Analysis of multicomponent liquid mixtures in terms of mole fraction or molality and their thermodynamic and volumetric properties are important for the design of industrial processes. These properties are also important in the search of models capable of correlating the molecular structure and macroscopic properties of liquids [2]. During the liquid mixture formation the changes of molecule interactions occur, and difference in the components packing becomes apparent. When there is developed hydrogen bond network in, at least, one of the solvents then the mixture properties change in a special way [3].

The physical properties of liquid mixtures are very important in understanding the nature of molecular interactions between the molecules of liquid mixtures. Such properties of liquid mixtures are useful in designing various transport and process equipments in the chemical industry [4].

An amphiphilic molecule possesses at the same time a polar and nonpolar group. In aqueous solutions, these molecules can self-associate into aggregates called micelles [5], where contact between water and hydrocarbon is greatly reduced while the polar groups maintain their hydration. In this process the main contributions to the free energy are the elimination of unfavorable hydrocarbon-water contacts, 
TABLE 1: Physical properties of pure component liquids at $298.15 \mathrm{~K}^{\mathrm{a}}$.

\begin{tabular}{|c|c|c|c|c|c|c|c|c|}
\hline \multirow{2}{*}{ Material } & \multirow{2}{*}{ Molar mass $\left(\mathrm{g} \cdot \mathrm{mol}^{-1}\right)$} & \multirow{2}{*}{ Purity \% } & \multicolumn{3}{|c|}{$\rho\left(\mathrm{g} \cdot \mathrm{cm}^{-1}\right)$} & \multicolumn{3}{|c|}{$n_{D}$} \\
\hline & & & Exp. & Lit. & Reference & Exp. & Lit. & Reference \\
\hline EG & 62.07 & $>99$ & 1.1063 & 1.1061 & [19] & 1.4303 & 1.4304 & [20] \\
\hline DEG & 106.12 & $>99$ & 1.1128 & 1.1129 & {$[12]$} & 1.4472 & 1.4467 & [20] \\
\hline TEG & 150.18 & $>99$ & 1.1195 & 1.1195 & {$[21]$} & 1.4562 & 1.4561 & [22] \\
\hline
\end{tabular}

${ }^{\text {a }}$ Standard uncertainties $u$ are $u(T)=0.01 \mathrm{~K}, u(\rho)=2.0 \times 10^{-5} \mathrm{~g} \cdot \mathrm{cm}^{-3}$, and $u\left(n_{D}\right)=2.0 \times 10^{-4}$.

the head-group interactions, and the interaggregate interactions $[6,7]$.

Hydration properties of solutes, that is, organic molecules and biomolecules in water mixtures, in general, reflect in a complex manner the combined effect of different heterogeneous interactions around the solute. The hydrophilic and hydrophobic hydration and interaction are the central topics in liquid state chemistry and physics. The interface of hydrophilic and hydrophobic effects with each other leads to destructive or, under certain conditions, the cooperative interaction [8].

Ethylene glycols are very interesting solvents owing to the presence of the oxy and hydroxyl groups in the same molecule. Due to this the formation of intra- and intermolecular hydrogen bonds between the $-\mathrm{O}-$ and $-\mathrm{OH}$ groups of the same or different molecules of ethylene glycols has been observed [9]. Despite their interesting characteristics and industrial importance, thermodynamic properties of mixtures containing ethylene glycols have not been studied extensively enough [10].

In the present work, we report the density of binary mixtures containing ethylene glycol (EG), diethylene glycol (DEG), and triethylene glycol (TEG) with water at temperatures ranging between 298.15 and $318.15 \mathrm{~K}$. Values of densities are correlated with temperature and molality. The experimental data have been used to calculate the partial molar volumes and thermal expansion coefficients.

\section{Experimental}

2.1. Chemicals. All the solvents used were of analytical grade and purchased from Fluka AG. Densities and refractive indices of the pure liquids were measured and the results are listed in Table 1 together with the literature data for comparison. These liquids were kept over freshly activated molecular sieves of type 4.A (Union Carbide) for several days before use to reduce the water content. Table 1 reported some chemical and physical properties of all chemicals used in this study.

2.2. Preparation of Solutions. All solutions were prepared by dissolving the appropriate amount (by mass) of each solute in deionized distilled water. Solutions of different molalities ranging from 0.0466 to $0.5297 \mathrm{~mol} \cdot \mathrm{kg}^{-1}$ for each solute were prepared in a $25 \mathrm{~cm}^{3}$ volumetric flask, using digital balance (Sartorius BL210 S) accurate to within $\pm 0.0001 \mathrm{~g}$. All solutions were left at least $24 \mathrm{hrs}$ before measurements to attain equilibrium. Densities, $\rho$, and refractive indices, $n_{D}$, of the pure liquids are compared with the published data (Table 1).

2.3. Density Measurements. An Anton Paar digital densimeter (model DMA 60/601) was employed for the determination of the densities of pure component liquids and the binary mixtures. The density measurements are based on the variation of the natural frequency of a tube oscillator filled with sample liquid with respect to the air. The measuring cell is embodied in its separate housing, complete with oscillator counter mass and thermostat connectors. The oscillator or sample tube, made of borosilicate glass, is fused into a dualwall glass cylinder, thus allowing temperature control to be carried out by water circulation from a constant temperature path. The temperature of the water path was kept constant to within $0.01 \mathrm{~K}$ with Haake digital thermostat. The precision of density measurements is estimated to be better than $10^{-4}$ $\left(\mathrm{g} \cdot \mathrm{cm}^{-3}\right)$.

\section{Results and Discussion}

3.1. Density. The experimental measured densities of binary mixtures of (water + ethylene glycols) at 293.15, 298.15, $303.15,308.15,313.15$, and $318.15 \mathrm{~K}$ are listed in Table 2. The obtained results of the densities of all binary mixtures are plotted as a function of the molality of solution $\left(\mathrm{m} / \mathrm{mol} \cdot \mathrm{kg}^{-1}\right)$, (Figure 1). Density values at different temperatures for the aqueous solutions of ethylene glycols are in a good agreement with those published by Sun and Teja [11] and Müller and Rasmussen [12].

Experimental densities for the various binary mixtures in the molality ranges studied obey equation of the type [13]

$$
\rho=a+b m+c m^{2} \text {. }
$$

The $a, b$, and $c$ coefficients for the $(\rho)$ versus $(m)$ plots are shown in Table 3 together with the standard deviation, $\sigma$, defined by

$$
\sigma=\left[\frac{\sum\left(\rho_{\mathrm{obs}}-\rho_{\mathrm{cal}}\right)^{2}}{N-P}\right]^{1 / 2},
$$

where $\left(\rho_{\text {obs }}\right)$ and $\left(\rho_{\text {cal }}\right)$ are the observed and calculated density values, respectively, $N$ is the number of experimental points and $P$ is the number of coefficients in (1). Fitted values of the constant $(a)$ in (1) compare well with the average density of water for the various density determinations of water obtained during the set of experiments performed for each solute at each temperature. 
TABLE 2: Experimental densities $\rho\left(\mathrm{g} \cdot \mathrm{cm}^{-3}\right)$ for all aqueous binary mixtures at different temperatures.

\begin{tabular}{|c|c|c|c|c|c|c|}
\hline \multicolumn{7}{|c|}{$\rho\left(\mathrm{g} \cdot \mathrm{cm}^{-3}\right)$} \\
\hline$m(\mathrm{~mol} / \mathrm{kg})$ & $293.15 \mathrm{~K}$ & $298.15 \mathrm{~K}$ & $303.15 \mathrm{~K}$ & $308.1 \mathrm{~K}$ & $313.15 \mathrm{~K}$ & $318.15 \mathrm{~K}$ \\
\hline \multicolumn{7}{|c|}{ EG } \\
\hline 0.0000 & 0.99823 & 0.99708 & 0.99561 & 0.99400 & 0.99222 & 0.99022 \\
\hline 0.0488 & 0.99838 & 0.99716 & 0.99577 & 0.99419 & 0.99240 & 0.99033 \\
\hline 0.0982 & 0.99890 & 0.99760 & 0.99601 & 0.99451 & 0.99278 & 0.99090 \\
\hline 0.1561 & 0.99923 & 0.99780 & 0.99640 & 0.99497 & 0.99312 & 0.99114 \\
\hline 0.2365 & 0.99965 & 0.99840 & 0.99698 & 0.99541 & 0.99361 & 0.99138 \\
\hline 0.2726 & 0.99989 & 0.99876 & 0.99730 & 0.99575 & 0.99399 & 0.99186 \\
\hline 0.3143 & 1.00031 & 0.99906 & 0.99752 & 0.99601 & 0.99425 & 0.99228 \\
\hline 0.3796 & 1.00075 & 0.99945 & 0.99798 & 0.99640 & 0.99473 & 0.99260 \\
\hline 0.4268 & 1.00103 & 0.99977 & 0.99830 & 0.99676 & 0.99495 & 0.99302 \\
\hline 0.5201 & 1.00163 & 1.00041 & 0.99894 & 0.99740 & 0.99553 & 0.99351 \\
\hline \multicolumn{7}{|c|}{ DEG } \\
\hline 0.0000 & 0.99823 & 0.99708 & 0.99561 & 0.99400 & 0.99222 & 0.99022 \\
\hline 0.0517 & 0.99893 & 0.99764 & 0.99604 & 0.99481 & 0.99294 & 0.99075 \\
\hline 0.1112 & 0.99998 & 0.99885 & 0.99736 & 0.99559 & 0.99366 & 0.99159 \\
\hline 0.1505 & 1.00050 & 0.99939 & 0.99805 & 0.99638 & 0.99435 & 0.99294 \\
\hline 0.1965 & 1.00110 & 0.99979 & 0.99843 & 0.99660 & 0.99521 & 0.99340 \\
\hline 0.2618 & 1.00199 & 1.00080 & 0.99929 & 0.99730 & 0.99577 & 0.99399 \\
\hline 0.3103 & 1.00247 & 1.00160 & 0.99981 & 0.99799 & 0.99612 & 0.99441 \\
\hline 0.3472 & 1.00295 & 1.00184 & 1.00012 & 0.99843 & 0.99658 & 0.99477 \\
\hline 0.4235 & 1.00410 & 1.00293 & 1.00128 & 0.99992 & 0.99774 & 0.99579 \\
\hline 0.4602 & 1.00484 & 1.00353 & 1.00221 & 1.00060 & 0.99893 & 0.99666 \\
\hline 0.5017 & 1.00550 & 1.00432 & 1.00285 & 1.00128 & 0.99941 & 0.99732 \\
\hline \multicolumn{7}{|c|}{ TEG } \\
\hline 0.0000 & 0.99823 & 0.99717 & 0.99587 & 0.99392 & 0.99187 & 0.99002 \\
\hline 0.0538 & 0.99943 & 0.99828 & 0.99697 & 0.99496 & 0.99269 & 0.99108 \\
\hline 0.0994 & 1.00069 & 0.99971 & 0.99824 & 0.99645 & 0.99452 & 0.99271 \\
\hline 0.1543 & 1.00158 & 1.00077 & 0.99935 & 0.99742 & 0.99549 & 0.99396 \\
\hline 0.2001 & 1.00272 & 1.00140 & 1.00005 & 0.99834 & 0.99653 & 0.99416 \\
\hline 0.2552 & 1.00403 & 1.00283 & 1.00128 & 0.99945 & 0.99764 & 0.99585 \\
\hline 0.3192 & 1.00494 & 1.00389 & 1.00285 & 1.00092 & 0.99913 & 0.99752 \\
\hline 0.3686 & 1.00564 & 1.00512 & 1.00341 & 1.00178 & 0.99977 & 0.99818 \\
\hline 0.4366 & 1.00743 & 1.00630 & 1.00498 & 1.00319 & 1.00128 & 0.99915 \\
\hline 0.4804 & 1.00878 & 1.00743 & 1.00586 & 1.00401 & 1.00192 & 0.99993 \\
\hline 0.5288 & 1.00942 & 1.00801 & 1.00667 & 1.00484 & 1.00293 & 1.00092 \\
\hline
\end{tabular}

${ }^{\text {a }}$ Standard uncertainties $u$ are: $u(T)=0.01 \mathrm{~K}, u(\rho)=2.0 \times 10^{-5} \mathrm{~g} \cdot \mathrm{cm}^{-3}$.

3.2. Partial Molar Volumes. The volumes of the investigated solutions, $V_{1,2}\left(\mathrm{~cm}^{3}\right)$, containing $m$ moles of solute per kilogram of solvent, were calculated from [14]

$$
V_{1,2}=\frac{\left(1000+m M_{2}\right)}{\rho}
$$

where $M_{2}\left(\mathrm{~g} \cdot \mathrm{mol}^{-1}\right)$ is the solute molecular weight and $(\rho)$ is the density of solution. The values of $\left(V_{1,2}\right)$ for investigated solutions are increased with increasing concentration. Figure 2 shows the plots of $\left(V_{1,2}\right)$ versus $(m)$ for all investigated solutes. We can reasonably assume that a "substitutional" mixing occurs for water + EGs systems, which transform gradually to an "interstitial" accommodation due to the possible cavity occupation by the hydrocarbon chain, the polar character of the second $(\mathrm{OH})$ group getting progressively less important. Reinforcement of the water structure becomes more and more important from water + EG to water + TEG systems. [15]

The concentration dependence of $V_{1,2}$ can be described by

$$
V_{1,2}=V_{S}^{0}+\bar{V}_{2,0} m+v_{22} m^{2}+v_{222} m^{3}+\cdots,
$$

where $\left(V_{S}^{0}=1000 / \rho_{1}^{\phi}\right), \rho_{1}^{\phi}\left(\mathrm{g} \cdot \mathrm{cm}^{-3}\right)$ is the density of the pure solvent, $\bar{V}_{2,0}\left(\mathrm{~cm}^{3} \cdot \mathrm{mol}^{-1}\right)$ is the partial molar volume of solute at infinite dilution, and $v_{22}, v_{222}$, and so forth are the virial 
TABle 3: Parameters in (1), $a /\left(\mathrm{g} \cdot \mathrm{cm}^{-3}\right), b /\left(\mathrm{g} \cdot \mathrm{cm}^{-3} \cdot \mathrm{mol}^{-1} \cdot \mathrm{kg}\right)$, and $c /\left(\mathrm{g} \cdot \mathrm{cm}^{-3} \cdot \mathrm{mol}^{-2} \cdot \mathrm{kg}^{2}\right)$ for all solutes together with $(\sigma)$ values.

\begin{tabular}{|c|c|c|c|c|c|c|}
\hline Temperature & $293.15 \mathrm{~K}$ & $298.15 \mathrm{~K}$ & $303.15 \mathrm{~K}$ & $308.15 \mathrm{~K}$ & $313.15 \mathrm{~K}$ & $318.15 \mathrm{~K}$ \\
\hline \multicolumn{7}{|c|}{ EG } \\
\hline$a$ & 0.99820 & 0.99705 & 0.99558 & 0.99397 & 0.99214 & 0.99016 \\
\hline$b$ & 0.0060 & 0.0037 & 0.0042 & 0.0055 & 0.0065 & 0.0061 \\
\hline$c$ & 0.0017 & 0.0087 & 0.0070 & 0.0034 & 0.0001 & 0.0008 \\
\hline$\sigma$ & 0.0001 & 0.0004 & 0.0003 & 0.0002 & 0.0001 & 0.0001 \\
\hline \multicolumn{7}{|c|}{ DEG } \\
\hline$a$ & 0.99832 & 0.99708 & 0.99565 & 0.99423 & 0.99236 & 0.99022 \\
\hline$b$ & 0.0134 & 0.0143 & 0.0134 & 0.0105 & 0.0115 & 0.0148 \\
\hline$c$ & 0.0013 & -0.0004 & 0.0012 & 0.0067 & 0.0047 & -0.0024 \\
\hline$\sigma$ & 0.0001 & 0.0002 & 0.0003 & 0.0002 & 0.0003 & 0.0003 \\
\hline \multicolumn{7}{|c|}{ TEG } \\
\hline$a$ & 0.99836 & 0.99721 & 0.99589 & 0.99391 & 0.99176 & 0.99009 \\
\hline$b$ & 0.0213 & 0.0228 & 0.0223 & 0.0234 & 0.0253 & 0.0257 \\
\hline$c$ & -0.0006 & -0.0042 & -0.0034 & -0.0051 & -0.0083 & -0.0098 \\
\hline$\sigma$ & 0.0003 & 0.0002 & 0.0002 & 0.0001 & 0.0003 & 0.0003 \\
\hline
\end{tabular}

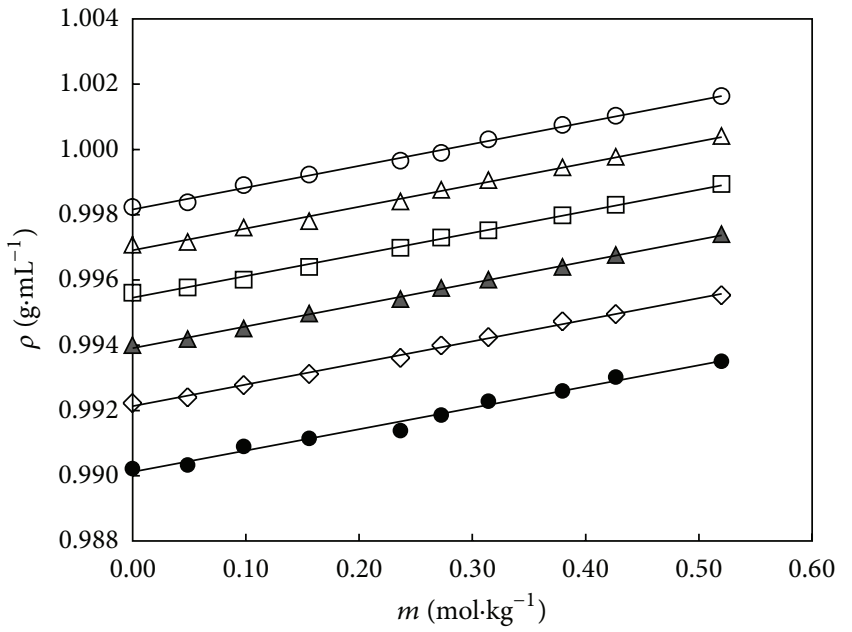

(a)

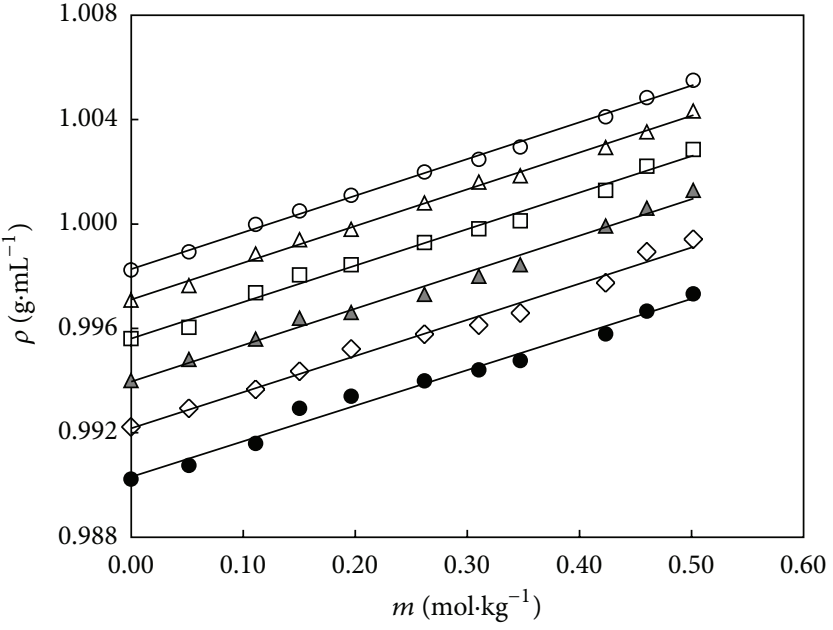

(b)

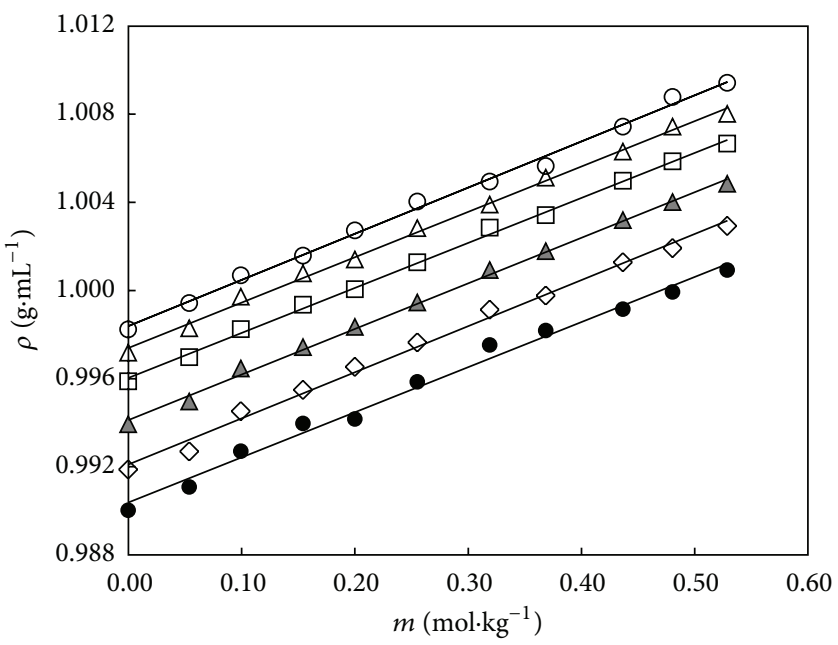

(c)

FIGURE 1: Density-concentration curves for aqueous solutions of (a) EG, (b) DEG, and (c) TEG, at temperatures, $T / K=293.15, O$; $T / K=$ $298.15, \triangle ; T / K=303.15, \square ; T / K=308.15, \boldsymbol{\Delta} ; T / K=313.15, \diamond ; T / K=318.15 \mathrm{~K}$, 


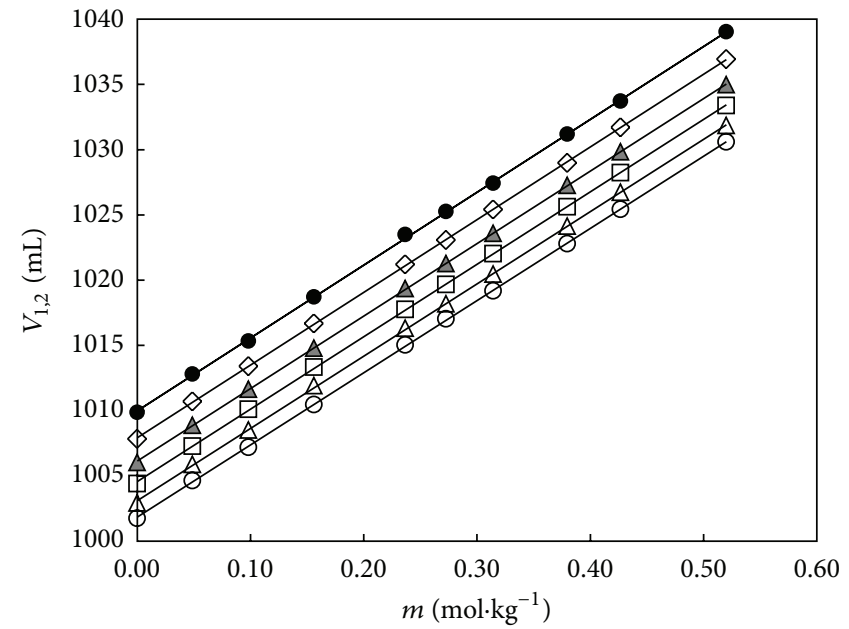

(a)

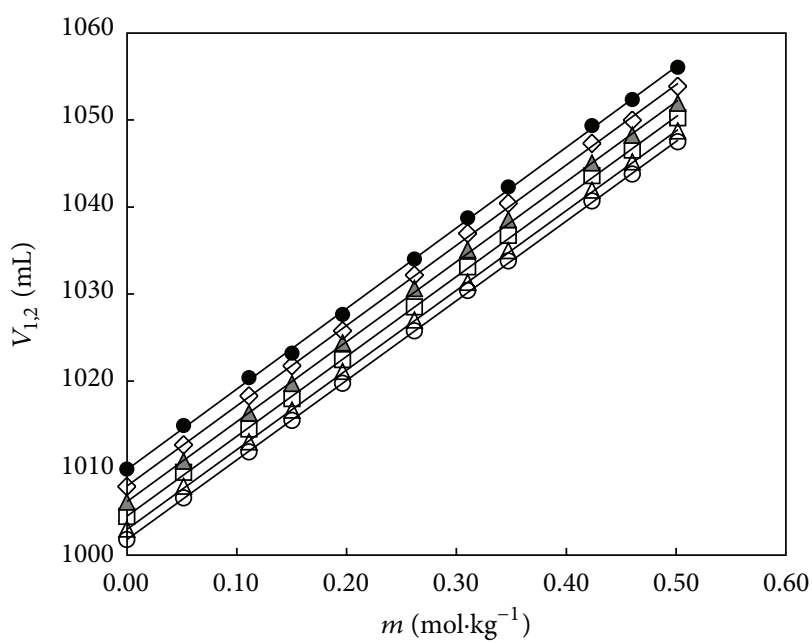

(b)

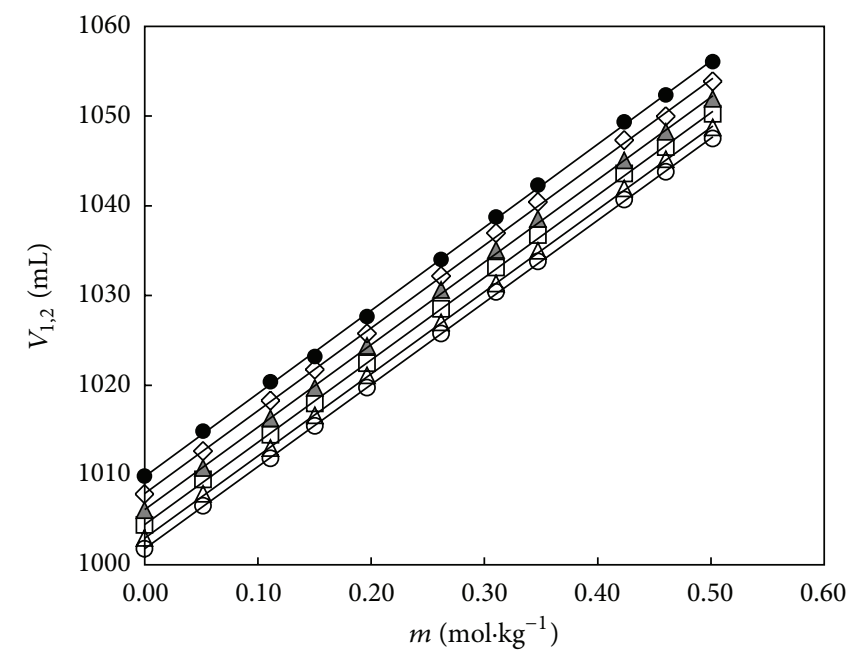

(c)

FIGURE 2: Volumes of aqueous solutions containing m mole of solute per kg of solvent: (a) EG, (b) DEG, and (c) TEG, at temperatures, T/K $=293.15, \bigcirc ; T / K=298.15, \triangle ; T / K=303.15, \square ; T / K=308.15, \Delta ; T / K=313.15, \diamond ; T / K=318.15 \mathrm{~K}$,

coefficients according to McMillan-Mayer theory of solution [16] and present the contribution to the excess thermodynamic properties of pair, triplet, and higher aggregates.

For the investigated solutions, it was found that the volumes of solution at a definite temperature for each solute are linearly dependent on the concentration of solute; that is, the relation (4) is reduced to

$$
V_{1,2}=V_{S}^{0}+\bar{V}_{2,0} m
$$

From this relation the partial molar volume at infinite dilution $\left(\bar{V}_{2,0}\right)$ for each solute at a definite temperature can be determined from the plots of $\left(V_{1,2}\right)$ as a function of molality $(m)$ (Figure 2$)$. The values of $\left(\bar{V}_{2,0}\right)$ together with the standard errors are given in Table 4 . The values of $\left(\bar{V}_{2,0}\right)$ are concentration independent and slightly increase with increasing temperature.
The partial molar volumes at infinite dilution or the limiting apparent molar volumes of EG oligomers can be fitted by the linear equations:

$$
\begin{array}{ll}
\bar{V}_{2,0}=36.34 n+18.92 & (293.15 \mathrm{~K}), \\
\bar{V}_{2,0}=36.52 n+18.76 & (298.15 \mathrm{~K}), \\
\bar{V}_{2,0}=36.55 n+18.86 & (303.15 \mathrm{~K}), \\
\bar{V}_{2,0}=36.62 n+18.85 & (308.15 \mathrm{~K}), \\
\bar{V}_{2,0}=36.67 n+18.96 & (313.15 \mathrm{~K}), \\
\bar{V}_{2,0}=36.87 n+18.92 & (318.15 \mathrm{~K}), \\
& (1 \leq n \leq 3),
\end{array}
$$

where $n$ is the number of oxyethylene $\left(\mathrm{CH}_{2} \mathrm{CH}_{2} \mathrm{O}\right)$ groups in the molecule. These equations outline a constant contribution 
TABLE 4: Partial molar volumes at infinite dilution $\left(\bar{V}_{2,0}\right)$ for all aqueous binary mixtures at different temperatures.

\begin{tabular}{|c|c|c|c|c|c|c|}
\hline \multicolumn{7}{|c|}{$\bar{V}_{2,0}\left(\mathrm{~cm}^{3} \cdot \mathrm{mol}^{-1}\right)$} \\
\hline Temperature & $293.15 \mathrm{~K}$ & $298.15 \mathrm{~K}$ & $303.15 \mathrm{~K}$ & $308.15 \mathrm{~K}$ & $313.15 \mathrm{~K}$ & $318.15 \mathrm{~K}$ \\
\hline $\mathrm{EG}$ & $55.29 \pm 0.08$ & $55.37 \pm 0.10$ & $55.47 \pm 0.08$ & $55.53 \pm 0.06$ & $55.67 \pm 0.07$ & $55.82 \pm 0.14$ \\
\hline DEG & $91.53 \pm 0.15$ & $91.60 \pm 0.15$ & $91.83 \pm 0.25$ & $91.96 \pm 0.29$ & $92.23 \pm 0.31$ & $92.60 \pm 0.32$ \\
\hline TEG & $127.97 \pm 0.26$ & $128.40 \pm 0.19$ & $128.57 \pm 0.17$ & $128.76 \pm 0.15$ & $129.01 \pm 0.26$ & $129.55 \pm 0.34$ \\
\hline
\end{tabular}

TABLE 5: Partial molecular volumes at infinite dilution $\bar{\nu}_{2,0}$, molecular volumes of pure solutes $\nu_{2}^{0}$, excess partial molecular volumes at infinite dilution $\bar{v}_{2,0}^{\text {exc }}$, and the ratio $\left(\bar{\nu}_{2,0} / \nu_{2}^{0}\right)$.

\begin{tabular}{|c|c|c|c|c|c|c|}
\hline Temperature/K & 293.15 & 298.15 & 303.15 & 308.15 & 313.15 & 318.15 \\
\hline \multicolumn{7}{|c|}{ EG } \\
\hline $\bar{v}_{2,0} \times 10^{23} \mathrm{~cm}^{3} \cdot$ molecule $^{-1}$ & 9.1813 & 9.1946 & 9.2112 & 9.2212 & 9.2444 & 9.2693 \\
\hline$v_{2}^{0} \times 10^{23} \mathrm{~cm}^{3} \cdot$ molecule $^{-1}$ & 9.3227 & 9.3168 & 9.3109 & 9.3051 & 9.2992 & 9.2933 \\
\hline $\bar{v}_{2,0} / \nu_{2}^{0}$ & 0.9848 & 0.9869 & 0.9893 & 0.9910 & 0.9941 & 0.9974 \\
\hline $\bar{\nu}_{2,0}^{\mathrm{exc}} \times 10^{24} \mathrm{~cm}^{3} \cdot$ molecule ${ }^{-1}$ & -0.1414 & -0.1222 & -0.0997 & -0.0839 & -0.0548 & -0.0240 \\
\hline \multicolumn{7}{|c|}{ DEG } \\
\hline $\bar{v}_{2,0} \times 10^{23} \mathrm{~cm}^{3} \cdot$ molecule $^{-1}$ & 15.1993 & 15.2109 & 15.2491 & 15.2707 & 15.3155 & 15.3770 \\
\hline$\nu_{2}^{0} \times 10^{23} \mathrm{~cm}^{3} \cdot$ molecule $^{-1}$ & 15.8604 & 15.8500 & 15.8396 & 15.8292 & 15.8189 & 15.8085 \\
\hline $\bar{v}_{2,0} / \nu_{2}^{0}$ & 0.9583 & 0.9597 & 0.9627 & 0.9647 & 0.9682 & 0.9727 \\
\hline $\bar{\nu}_{2,0}^{\mathrm{exc}} \times 10^{24} \mathrm{~cm}^{3} \cdot$ molecule ${ }^{-1}$ & -0.6611 & -0.6391 & -0.5905 & -0.5585 & -0.5034 & -0.4315 \\
\hline \multicolumn{7}{|c|}{ TEG } \\
\hline $\bar{v}_{2,0} \times 10^{23} \mathrm{~cm}^{3} \cdot$ molecule $^{-1}$ & 21.2504 & 21.3218 & 21.3500 & 21.3816 & 21.4231 & 21.5128 \\
\hline$v_{2}^{0} \times 10^{23} \mathrm{~cm}^{3} \cdot$ molecule $^{-1}$ & 22.2920 & 22.2765 & 22.2610 & 22.2455 & 22.2300 & 22.2146 \\
\hline $\bar{v}_{2,0} / \nu_{2}^{0}$ & 0.9533 & 0.9571 & 0.9591 & 0.9612 & 0.9637 & 0.9684 \\
\hline $\bar{v}_{2,0}^{\mathrm{exc}} \times 10^{24} \mathrm{~cm}^{3} \cdot$ molecule $^{-1}$ & -1.0416 & -0.9547 & -0.9110 & -0.8639 & -0.8069 & -0.7018 \\
\hline
\end{tabular}

of the oxyethylene $\left(\mathrm{CH}_{2} \mathrm{CH}_{2} \mathrm{O}\right)$ group and the terminal $(\mathrm{OH})$ group to the volumetric properties. The linearity of $\left(\bar{V}_{2,0}\right)$ with $n$ and then with the molecular weight, is typical for rod-like molecules, and, on the other hand, it is reasonable to hypothesize this shape for the first oligomer molecules. The volume contribution value for the ethoxyl group ranging from 36.34 to $36.87 \mathrm{~cm}^{3} \cdot \mathrm{mol}^{-1}$ is in a good agreement with the value reported by Vergara et al. [17] $\left(37.18 \mathrm{~cm}^{3} \cdot \mathrm{mol}^{-1}\right)$ or that reported by Kirinčič and Klofu$\operatorname{tar}[18]\left(36.9 \mathrm{~cm}^{3} \cdot \mathrm{mol}^{-1}\right)$ or the value derived from group contribution theory $\left(36.1 \mathrm{~cm}^{3} \cdot \mathrm{mol}^{-1}\right)$. Furthermore this value increases with increasing temperature which suggests that the contribution of the oxyethylene group increase with temperature. The average value of hydroxyl group contribution is $18.88 \mathrm{~cm}^{3} \cdot \mathrm{mol}^{-1}$ which is a comparable amount with the literature value $\left(17.54 \mathrm{~cm}^{3} \cdot \mathrm{mol}^{-1}\right)$ [17].

The partial molecular volumes at infinite dilution $\left(\mathrm{cm}^{3} \cdot \mathrm{molecule}^{-1}\right)$ for the investigated liquid solutes at 298.15 K were calculated from:

$$
\bar{v}_{2,0}=\frac{\bar{V}_{2,0}}{N_{A}},
$$

where $N_{A}$ is Avogadro's constant. The molecular volumes of the pure liquid solutes $\left(\mathrm{cm}^{3} \cdot\right.$ molecule $\left.^{-1}\right)$ at $298.15 \mathrm{~K}$ were calculated from

$$
v_{2}^{0}=\frac{M_{2}}{\rho_{2}^{\phi} N_{A}},
$$

where $\left(\rho_{2}^{\phi}\right)$ is the density of the pure solute. A comparison of the partial molecular volumes at infinite dilution $\left(\bar{\nu}_{2,0}\right)$ for all solutes with their molecular volumes $\left(\nu_{2}^{0}\right)$ shows that the former are smaller than the latter. Values of $\bar{v}_{2,0}$ and $v_{2}^{0}$ together with the values of their ratio $\left(\bar{\nu}_{2,0} / \nu_{2}^{0}\right)$ are given in Table 5. The values of the partial excess molecular volumes were calculated from

$$
\bar{\nu}_{2,0}^{\mathrm{exc}}=\bar{v}_{2,0}-v_{2}^{0}
$$

These values, which characterize the volume changes associated with the transfer of one molecule of solute from the pure solute to solution at infinite dilution, are negative increase in magnitude with increasing oxyethylene units, and decrease with increasing temperature. 


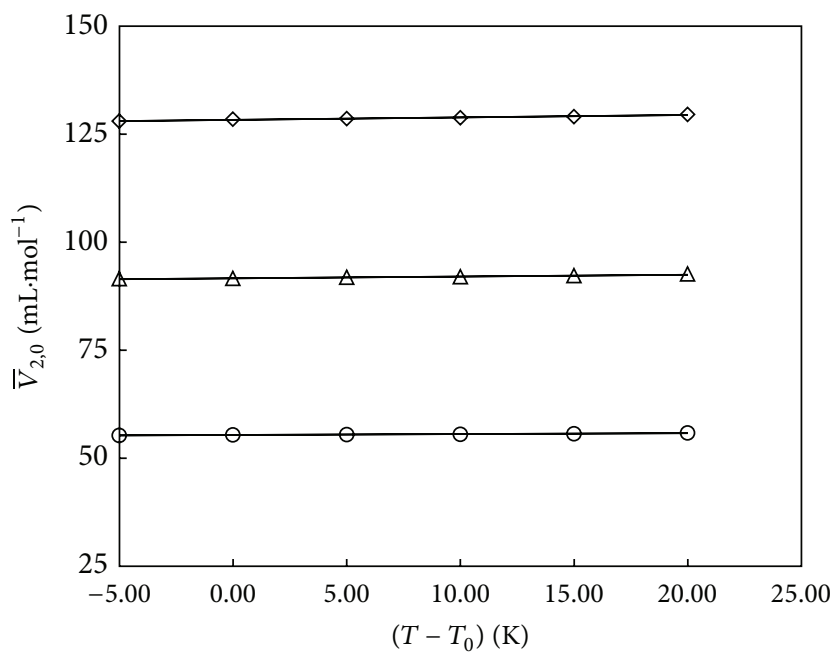

FIGURE 3: The temperature dependence of the partial molar volume at infinite dilution for aqueous solutions of $(\mathrm{OEG} ; \triangle \mathrm{DEG} \diamond \diamond \mathrm{TEG})$.

TABLE 6: Regression coefficients of $(10)$ and the ratio $\left(a_{1} / a_{0}\right)$ at the temperature range studied.

\begin{tabular}{lcccc}
\hline Solute & $a_{0}$ & $a_{1}$ & $\left(a_{1} / a_{0}\right) \times 10^{4} / \mathrm{K}^{-1}$ & $R^{2}$ \\
\hline EG & 55.37 & 0.021 & 3.793 & 0.978 \\
DEG & 91.64 & 0.042 & 4.583 & 0.953 \\
TEG & 128.28 & 0.057 & 4.443 & 0.964 \\
\hline
\end{tabular}

3.3. Thermal Expansion Coefficients. The partial molar volumes at infinite dilution for all investigated aqueous solutions, listed in Table 4, are slightly temperature dependent. From Figure 3 it can be seen that the plots of $\left(\bar{V}_{2,0}\right)$ against $\left(T-T_{o}\right)$ are linear, so it can described by

$$
\bar{V}_{2,0}=a_{0}+a_{1}\left(T-T_{0}\right),
$$

where $a_{o}$ and $a_{1}$ are empirical constants and $T$ is the absolute temperature; $T_{0}=298.15 \mathrm{~K}$. The coefficients $a_{o}$ and $a_{1}$, determined by the method of least squares, are given in Table 6.

As the partial molar volumes of all investigated solutes in water are concentration independent and equal to their volumes at infinite dilution, so the values of the partial molar expansibility of the solute $\left(\bar{E}_{2}=\left(\partial \bar{V}_{2} / \partial T\right)_{P}\right)\left(\mathrm{cm}^{3} \cdot \mathrm{mol}^{-1} \cdot \mathrm{K}^{-1}\right)$ are also concentration independent and equal to their values at infinite dilution $\left(\bar{E}_{2}=\bar{E}_{2,0}\right)$.

The partial molar expansibility of the solute at infinite dilution is equal to the regression coefficient $\alpha_{1}$ of (10), and the thermal expansion coefficient of the solute at infinite dilution $\left(\alpha_{2,0}\right)\left(\mathrm{K}^{-1}\right)$ is defined as [14]

$$
\alpha_{2,0}=\frac{1}{\bar{V}_{2,0}}\left(\frac{\partial \bar{V}_{2,0}}{\partial T}\right)_{P}=\frac{\bar{E}_{2,0}}{\bar{V}_{2,0}}
$$

which is equal to the ratio $a_{1} / a_{0}$. The values of $\left(\alpha_{2,0}\right)$ calculated from (11) are given in Table 7. The values of $\left(\alpha_{2,0}\right)$ tend to decrease slightly with increasing temperature. On the other hand, the thermal expansion coefficient of solution $\alpha_{1,2}\left(\mathrm{~K}^{-1}\right)$ is defined as

$$
\alpha_{1,2}=\frac{1}{V_{1,2}}\left(\frac{\partial V_{1,2}}{\partial T}\right)_{P},
$$

where $V_{1,2}$ is the volume of solution containing m mole of solute per kilogram of solvent. Thus, the thermal expansion coefficient of the investigated solutions is calculated from

$$
\alpha_{1,2}=\frac{1}{V_{1,2}}\left(\frac{10^{3}}{\rho_{1}^{\phi}} \alpha_{1}^{0}+m \bar{E}_{2,0}\right),
$$

where $\alpha_{1}^{0}$ is the thermal expansion coefficient of pure water.

The values of $\alpha_{1,2}$ for all investigated solutions are given in Table 8 . The thermal expansion coefficients for all solutes increase with increasing temperature and molality. The dependence of $\left(\alpha_{1,2}-\alpha_{1}^{0}\right)$ against the volume fraction of solute $(\Phi)$ is shown in Figure 4 . The volume fraction was used instead of molality or mole fraction of solute to allow for the effects of size differences of solute and solvent molecules. The volume fraction of solute was calculated from

$$
\Phi=\frac{m \bar{V}_{2,0}}{1000 / \rho_{1}^{\phi}+m \bar{V}_{2,0}} .
$$

From Figure 4, it can be seen that the dependence of $\left(\alpha_{1,2}-\alpha_{1}^{0}\right)$ on $(\Phi)$ is linear. This dependence may be expressed in the form [14]

$$
\alpha_{1,2}-\alpha_{1}^{0}=\left(\alpha_{2,0}-\alpha_{1}^{0}\right) \Phi
$$


TABLE 7: Thermal expansion coefficients at infinite dilution $\left(\alpha_{2,0}\right)$ at the temperature range studied.

\begin{tabular}{|c|c|c|c|c|c|c|}
\hline \multicolumn{7}{|c|}{$\alpha_{2,0} \times 10^{4}\left(\mathrm{~K}^{-1}\right)$} \\
\hline Solute & $293.15 \mathrm{~K}$ & $298.15 \mathrm{~K}$ & $303.15 \mathrm{~K}$ & $308.15 \mathrm{~K}$ & $313.15 \mathrm{~K}$ & $318.15 \mathrm{~K}$ \\
\hline EG & 3.798 & 3.793 & 3.786 & 3.782 & 3.772 & 3.762 \\
\hline DEG & 4.589 & 4.585 & 4.574 & 4.567 & 4.554 & 4.536 \\
\hline TEG & 4.454 & 4.439 & 4.433 & 4.427 & 4.418 & 4.400 \\
\hline
\end{tabular}

TABLE 8: Values of the thermal expansion coefficients $\alpha_{1,2} \times 10^{4}\left(\mathrm{~K}^{-1}\right)$ and the volume fraction $(\Phi)$ of the investigated solutions.

\begin{tabular}{|c|c|c|c|c|c|c|c|}
\hline \multicolumn{8}{|c|}{$\alpha_{2,0} \times 10^{4}\left(\mathrm{~K}^{-1}\right)$} \\
\hline $\mathrm{m} /\left(\mathrm{mol} \cdot \mathrm{kg}^{-1}\right)$ & $\Phi$ & $293.15 \mathrm{~K}$ & $298.15 \mathrm{~K}$ & $303.15 \mathrm{~K}$ & $308.15 \mathrm{~K}$ & $313.15 \mathrm{~K}$ & $318.15 \mathrm{~K}$ \\
\hline \multicolumn{8}{|c|}{ EG } \\
\hline 0.0000 & 0.0000 & 2.0666 & 2.5690 & 3.0263 & 3.4464 & 3.8352 & 4.1974 \\
\hline 0.0488 & 0.0027 & 2.0709 & 2.5716 & 3.0278 & 3.4468 & 3.8345 & 4.1953 \\
\hline 0.0982 & 0.0054 & 2.0759 & 2.5752 & 3.0296 & 3.4477 & 3.8345 & 4.1951 \\
\hline 0.1561 & 0.0085 & 2.0813 & 2.5786 & 3.0320 & 3.4490 & 3.8341 & 4.1931 \\
\hline 0.2365 & 0.0129 & 2.0885 & 2.5840 & 3.0354 & 3.4501 & 3.8336 & 4.1901 \\
\hline 0.2726 & 0.0148 & 2.0919 & 2.5867 & 3.0371 & 3.4511 & 3.8341 & 4.1902 \\
\hline 0.3143 & 0.0171 & 2.0960 & 2.5895 & 3.0387 & 3.4518 & 3.8339 & 4.1899 \\
\hline 0.3796 & 0.0205 & 2.1021 & 2.5937 & 3.0414 & 3.4528 & 3.8338 & 4.1879 \\
\hline 0.4268 & 0.0230 & 2.1063 & 2.5967 & 3.0433 & 3.4538 & 3.8334 & 4.1873 \\
\hline 0.5201 & 0.0279 & 2.1148 & 2.6028 & 3.0472 & 3.4556 & 3.8330 & 4.1847 \\
\hline \multicolumn{8}{|c|}{ DEG } \\
\hline 0.0000 & 0.0000 & 2.0666 & 2.5690 & 3.0263 & 3.4464 & 3.8352 & 4.1974 \\
\hline 0.0517 & 0.0047 & 2.0783 & 2.5780 & 3.0326 & 3.4519 & 3.8385 & 4.1981 \\
\hline 0.1112 & 0.0101 & 2.0922 & 2.5896 & 3.0423 & 3.4576 & 3.8418 & 4.2000 \\
\hline 0.1505 & 0.0136 & 2.1010 & 2.5967 & 3.0481 & 3.4623 & 3.8449 & 4.2045 \\
\hline 0.1965 & 0.0176 & 2.1111 & 2.6042 & 3.0536 & 3.4654 & 3.8486 & 4.2052 \\
\hline 0.2618 & 0.0234 & 2.1255 & 2.6160 & 3.0623 & 3.4710 & 3.8514 & 4.2058 \\
\hline 0.3103 & 0.0276 & 2.1357 & 2.6248 & 3.0683 & 3.4758 & 3.8532 & 4.2062 \\
\hline 0.3472 & 0.0307 & 2.1436 & 2.6304 & 3.0726 & 3.4791 & 3.8553 & 4.2067 \\
\hline 0.4235 & 0.0372 & 2.1603 & 2.6437 & 3.0831 & 3.4880 & 3.8605 & 4.2090 \\
\hline 0.4602 & 0.0403 & 2.1686 & 2.6502 & 3.0892 & 3.4921 & 3.8654 & 4.2117 \\
\hline 0.5017 & 0.0438 & 2.1776 & 2.6578 & 3.0948 & 3.4965 & 3.8677 & 4.2133 \\
\hline \multicolumn{8}{|c|}{ TEG } \\
\hline 0.0000 & 0.0000 & 2.0666 & 2.5690 & 3.0263 & 3.4464 & 3.8352 & 4.1974 \\
\hline 0.0538 & 0.0068 & 2.0829 & 2.5818 & 3.0365 & 3.4522 & 3.8365 & 4.1975 \\
\hline 0.0994 & 0.0126 & 2.0971 & 2.5937 & 3.0454 & 3.4597 & 3.8431 & 4.2015 \\
\hline 0.1543 & 0.0194 & 2.1127 & 2.6061 & 3.0548 & 3.4657 & 3.8463 & 4.2033 \\
\hline 0.2001 & 0.0250 & 2.1264 & 2.6157 & 3.0618 & 3.4710 & 3.8498 & 4.2012 \\
\hline 0.2552 & 0.0316 & 2.1425 & 2.6289 & 3.0715 & 3.4774 & 3.8536 & 4.2049 \\
\hline 0.3192 & 0.0393 & 2.1598 & 2.6425 & 3.0830 & 3.4854 & 3.8587 & 4.2081 \\
\hline 0.3686 & 0.0451 & 2.1729 & 2.6540 & 3.0898 & 3.4906 & 3.8607 & 4.2079 \\
\hline 0.4366 & 0.0529 & 2.1926 & 2.6682 & 3.1015 & 3.4985 & 3.8659 & 4.2080 \\
\hline 0.4804 & 0.0579 & 2.2055 & 2.6783 & 3.1086 & 3.5033 & 3.8680 & 4.2087 \\
\hline 0.5288 & 0.0634 & 2.2179 & 2.6876 & 3.1159 & 3.5082 & 3.8715 & 4.2101 \\
\hline
\end{tabular}


TABLE 9: Values of $\left(\alpha_{2,0}-\alpha_{1}^{0}\right)$ for all investigated solutions together with correlation coefficients $\left(r^{2}\right)$.

\begin{tabular}{lcccccc}
\hline Solute & $293.15 \mathrm{~K}$ & $298.15 \mathrm{~K}$ & $303.15 \mathrm{~K}$ & $308.15 \mathrm{~K}$ & $313.15 \mathrm{~K}$ & $318.15 \mathrm{~K}$ \\
\hline EG & 173.20 & 122.48 & 76.06 & 33.61 & -6.31 & 0.939 .62 \\
$r^{2}$ & 1.000 & 1.000 & 0.999 & 154.80 & 112.05 & 72.00 \\
\hline DEG & 252.17 & 201.55 & 1.000 & 0.999 & 0.997 & 33.94 \\
$r^{2}$ & 1.000 & 1.000 & 142.244 & 98.288 & 57.440 & 0.984 \\
\hline TEG & 238.440 & 188.028 & 1.000 & 1.000 & 0.998 & 0.976 \\
$r^{2}$ & 1.000 & 1.000 & & &
\end{tabular}

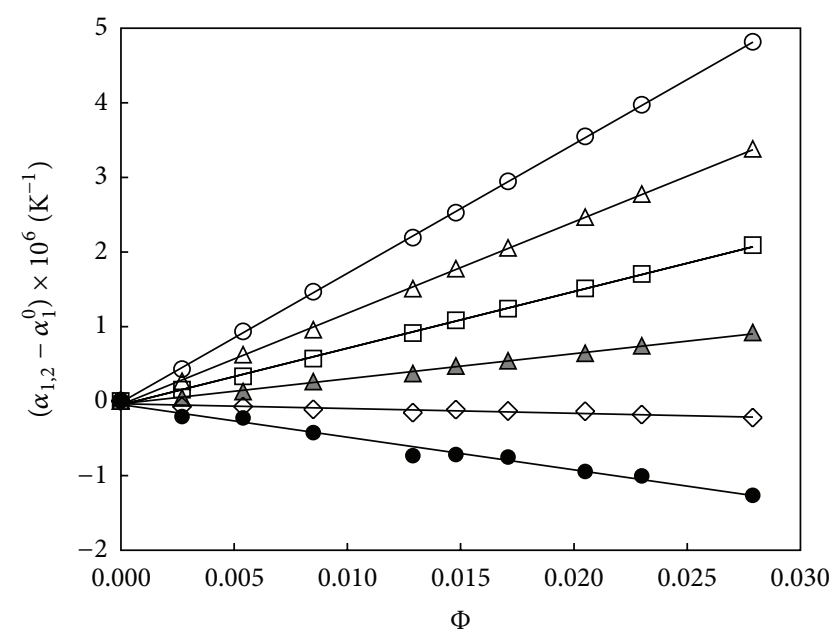

(a)

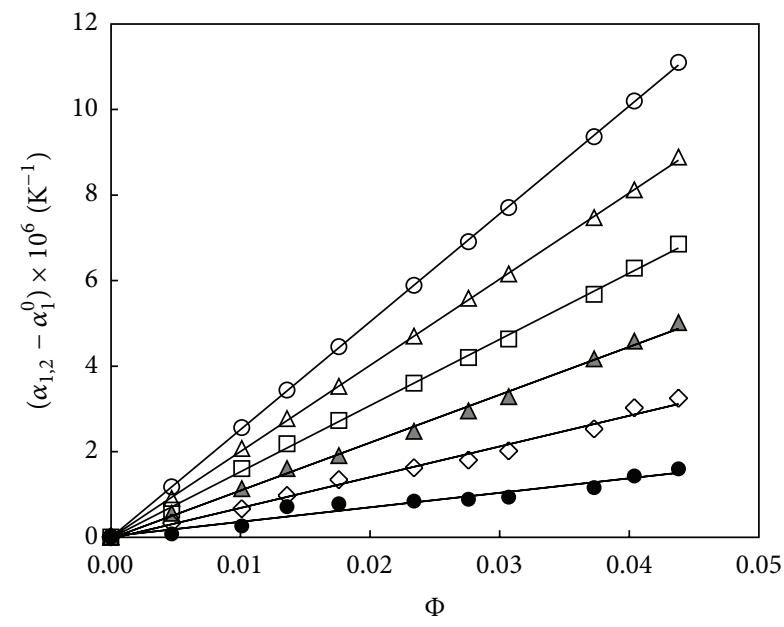

(b)

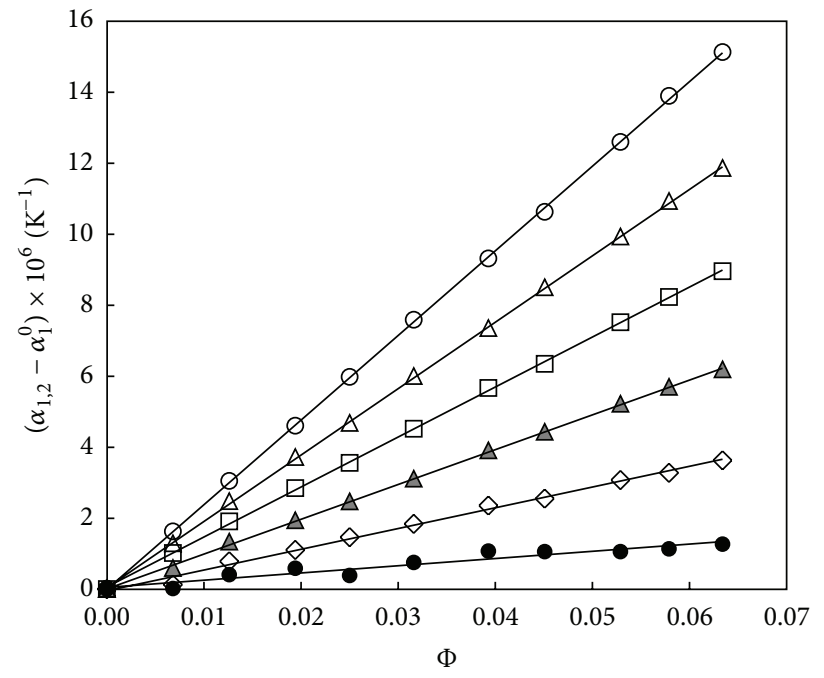

(c)

Figure 4: Dependence of $\left(\alpha_{1,2}-\alpha_{1}^{0}\right)$ on volume fraction of solute $(\Phi)$ for: (a) EG, (b) DEG, and (c) TEG, at temperatures, T/K=293.15, O; $T / K=298.15, \triangle ; T / K=303.15, \square ; T / K=308.15, \Delta ; T / K=313.15, \diamond ; T / K=318.15 \mathrm{~K}$,

The calculated values of $\left(\alpha_{1,2}-\alpha_{1}^{0}\right)$ are given in Table 9. From Figure 4 and Table 9 it can be seen that the values of the thermal expansion coefficient of the investigated solutions are higher than those of the pure solvent except in the case of ethylene glycol at higher temperatures ( 313.15 and $318.15 \mathrm{~K}$ ) where the thermal expansion coefficient of the solution is lower than that of the pure solvent. The low values for TEG may be indicative of the presence of entanglements of the chain in a coiled structure [17].

\section{Conclusions}

Density data and molar volumes as a function of temperature and molality are measured for aqueous solutions of ethylene 
glycol, diethylene glycol, and triethylene glycol. These data were used to derive the partial molar volume at infinite dilution $\left(\bar{V}_{2,0}\right) \cdot \bar{V}_{2,0}$ values were found to be slightly increased with increasing temperature. These values are correlated with the number of oxyethylene $\left(\mathrm{CH}_{2} \mathrm{CH}_{2} \mathrm{O}\right)$ groups in the molecule $(n)$. It was assumed that a constant contribution of the terminal $(\mathrm{OH})$ group and $\left(\mathrm{CH}_{2} \mathrm{CH}_{2} \mathrm{O}\right)$ group to the volumetric properties of these mixtures. The values of the partial excess molecular volumes $\left(\bar{\nu}_{2,0}^{\text {exc }}\right)$ were also calculated. These values are negative and increase in magnitude with increasing oxyethylene units and decreasing temperature.

The thermal expansion coefficients $\left(\alpha_{1,2}\right)$ for all solutes increase with increasing temperature and molality. It was found that the values of the thermal expansion coefficient of the investigated solutions are higher than those of the pure solvent except in the case of ethylene glycol at higher temperatures ( 313.15 and $318.15 \mathrm{~K})$ where the thermal expansion coefficient of the solution is lower than that of the pure solvent.

\section{Conflict of Interests}

The authors declare that there is no conflict of interests regarding the publication of this paper.

\section{References}

[1] A. Maitra and S. Bagchi, "Study of solute-solvent and solventsolvent interactions in pure and mixed binary solvents," Journal of Molecular Liquids, vol. 137, no. 1-3, pp. 131-137, 2008.

[2] F. Kermanpour, H. Jahani, and H. Iloukhani, "Excess molar volume and derived thermodynamic properties of binary mixtures of 2-methyl-1-butanol and 2-ethyl-1-butanol + different ethers at the temperature range of 293.15 to $313.15 \mathrm{~K}$," Journal of Molecular Liquids, vol. 146, no. 1-2, pp. 29-34, 2009.

[3] G. I. Egorov, D. M. Makarov, and A. M. Kolker, "Liquid phase PVTx properties of binary mixtures of (water + ethylene glycol) in the range from 278.15 to $323.15 \mathrm{~K}$ and from 0.1 to $100 \mathrm{MPa}$. I. Experimental results, partial and excess thermodynamics properties," Fluid Phase Equilibria, vol. 344, pp. 125-138, 2013.

[4] K. Zhang, J. Yang, X. Yu, J. Zhang, and X. Wei, "Densities and viscosities for binary mixtures of poly(ethylene glycol) $400+$ dimethyl sulfoxide and poly(ethylene glycol) $600+$ water at different temperatures," Journal of Chemical and Engineering Data, vol. 56, no. 7, pp. 3083-3088, 2011.

[5] R. G. Laughlin, "Relative hydrophilicities among surfactant hydrophilic groups," in Advances in Liquid Crystals, G. H. Brown, Ed., pp. 41-98, Academic Press, New York, NY, USA, 1978.

[6] L. Ambrosone, G. D'Errico, R. Sartorio, and L. Costantino, "Dynamic properties of aqueous solutions of ethylene glycol oligomers as measured by the pulsed gradient spin-echo NMR technique at $25^{\circ}$ C," Journal of the Chemical Society, vol. 93, no. 22, pp. 3961-3966, 1997.

[7] J. C. Lang and R. D. Morgan, "Nonionic surfactant mixtures. I. Phase equilibria in $\mathrm{C}_{10} \mathrm{E}_{4}-\mathrm{H}_{2} \mathrm{O}$ and closed-loop coexistence," The Journal of Chemical Physics, vol. 73, no. 11, pp. 5849-5861, 1980.

[8] R. J. Sengwa and S. Sankhla, "Characterization of heterogeneous interaction in binary mixtures of ethylene glycol oligomer with water, ethyl alcohol and dioxane by dielectric analysis," Journal of Molecular Liquids, vol. 130, no. 1-3, pp. 119-131, 2007.

[9] C. M. Kinart, M. Klimczak, and W. J. Kinart, "Volumetric and dielectric characterization and analysis of internal structure of binary mixtures of 2-ethoxyethanol with ethylene glycol, diethylene glycol, triethylene glycol, and tetraethylene glycol at $\mathrm{T}=(293.15,298.15$ and 303.15) K," Journal of Molecular Liquids, vol. 145, no. 1, pp. 8-13, 2009.

[10] I. A. Sedov, M. A. Stolov, and B. N. Solomonov, "Enthalpies and Gibbs free energies of solvation in ethylene glycol at $298 \mathrm{~K}$ : influence of the solvophobic effect," Fluid Phase Equilibria, vol. 354, pp. 95-101, 2013.

[11] T. Sun and A. S. Teja, "Density, viscosity, and thermal conductivity of aqueous ethylene, diethylene, and triethylene glycol mixtures between $290 \mathrm{~K}$ and $450 \mathrm{~K}$," Journal of Chemical and Engineering Data, vol. 48, no. 1, pp. 198-202, 2003.

[12] E. A. Müller and P. Rasmussen, "Densities and excess volumes in aqueous poly(ethylene glycol) solutions," Journal of Chemical and Engineering Data, vol. 36, no. 2, pp. 214-217, 1991.

[13] E. F. G. Barbosa, S. M. C. Sousa, M. S. C. S. Santos, and I. M. S. Lampreia, "Partial molar volumes of linear hydrocarbons in methanol in the very dilute region. Intermolecular interactions. H-bond effects," Physical Chemistry Chemical Physics, vol. 3, no. 4, pp. 556-561, 2001.

[14] C. Klofutar, Š. Paljk, and S. Golc-Teger, "Partial molar volumes and partial molar expansibilities of cholesterol in some aprotic solvents," Thermochimica Acta, vol. 196, no. 2, pp. 401-413, 1992.

[15] S. Wurzburger, R. Sartorio, G. Guarino, and M. Nisi, "Volumetric properties of aqueous solutions of polyols between 0.5 and $25^{\circ}$ C, Journal of the Chemical Society, Faraday Transactions 1 , vol. 84, no. 7, pp. 2279-2287, 1988.

[16] W. G. McMillan Jr. and J. E. Mayer, "The statistical thermodynamics of multicomponent systems," The Journal of Chemical Physics, vol. 13, no. 7, pp. 276-305, 1945.

[17] A. Vergara, L. Paduano, F. Capuano, and R. Sartorio, "Kirkwood-Buff integrals for polymer-solvent mixtures. Preferential solvation and volumetric analysis in aqueous PEG solutions," Physical Chemistry Chemical Physics, vol. 4, no. 19, pp. 47164723, 2002.

[18] S. Kirinčič and C. Klofutar, "A volumetric study of aqueous solutions of poly(ethylene glycol)s at $298.15 \mathrm{~K}$," Fluid Phase Equilibria, vol. 149, no. 1-2, pp. 233-247, 1998.

[19] T. M. Aminabhavi and K. Banerjee, "Density, viscosity, refractive index, and speed of sound in binary mixtures of methyl acetate + ethylene glycol or + poly(ethylene glycol) in the temperature interval (298.15-308.15) K," Journal of Chemical and Engineering Data, vol. 43, no. 5, pp. 852-855, 1998.

[20] J. George and N. V. Sastry, "Partial excess molar volumes, partial excess isentropic compressibilities and relative permittivities of water + ethane-1,2-diol derivative and water + 1,2-dimethoxyethane at different temperatures," Fluid Phase Equilibria, vol. 216, no. 2, pp. 307-321, 2004.

[21] S. L. Oswal and N. B. Patel, "Speed of sound, isentropic compressibility, viscosity, and excess volume of binary mixtures. 1. Alkanenitriles with alkyl acetates," Journal of Chemical \& Engineering Data, vol. 40, no. 4, pp. 840-844, 1995.

[22] J. A. Riddick, W. B. Bunger, and T. K. Sakano, Techniques of Chemistry. Organic Solvents. Physical Properties and Methods of Purification, vol. 2, John Wiley \& Sons, New York, NY, USA, 4th edition, 1986. 

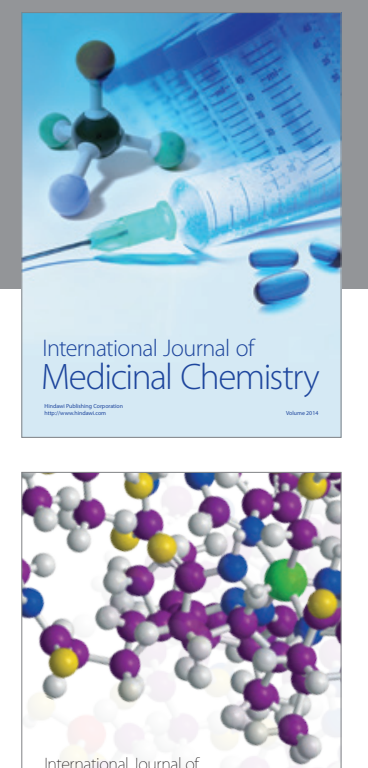

\section{Carbohydrate} Chemistry

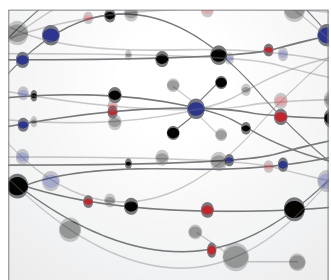

The Scientific World Journal
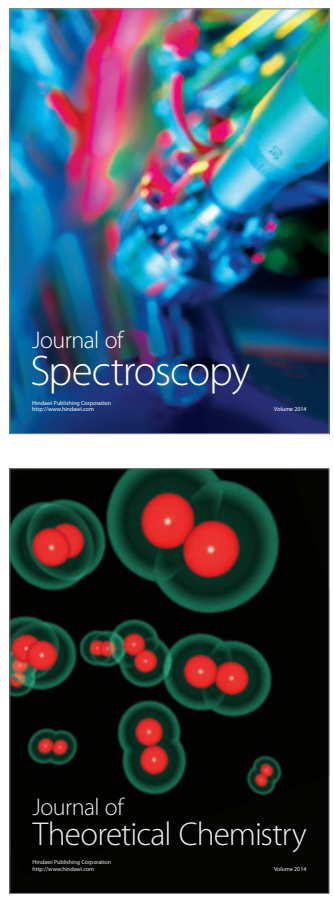
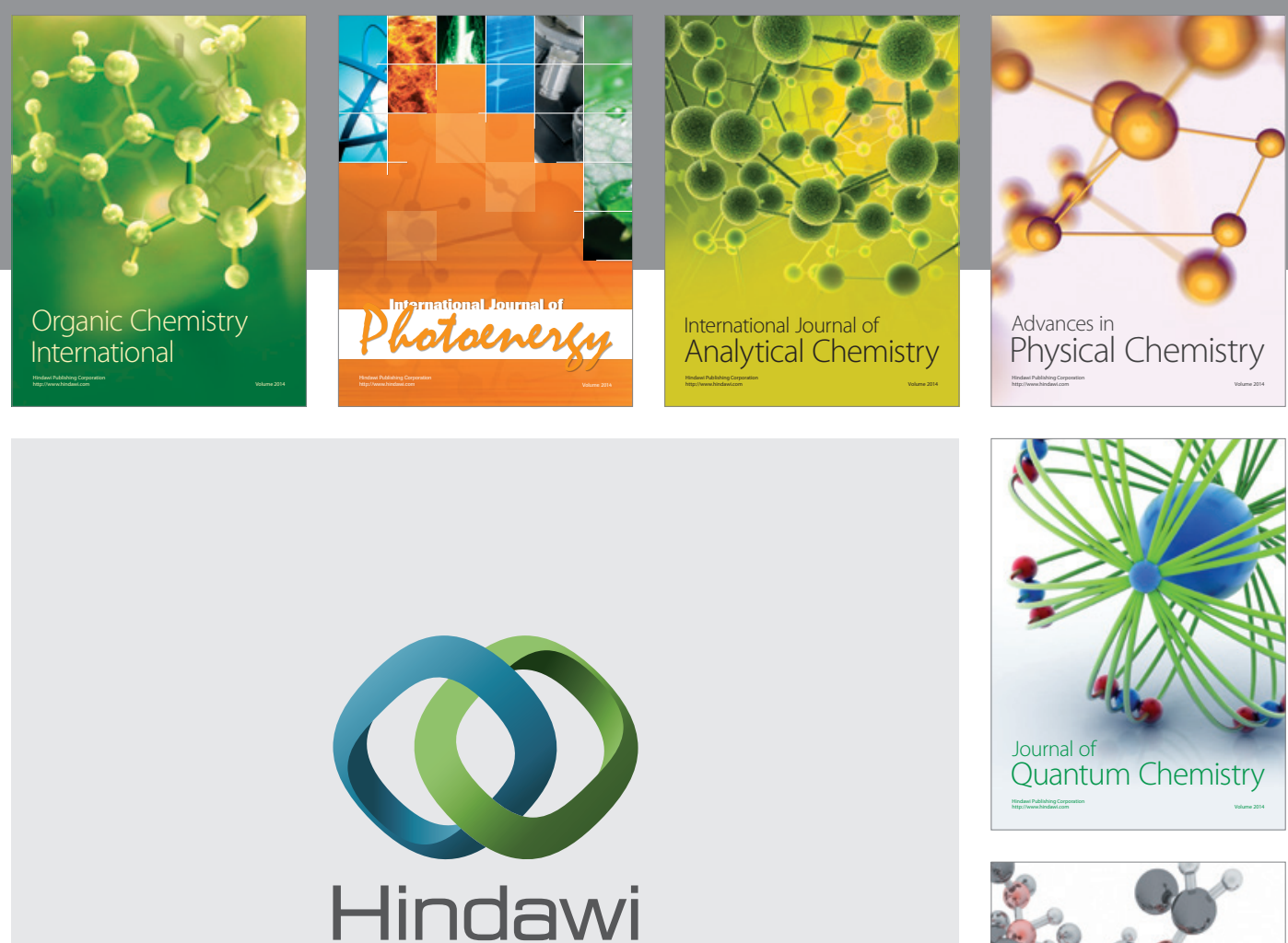

Submit your manuscripts at

http://www.hindawi.com

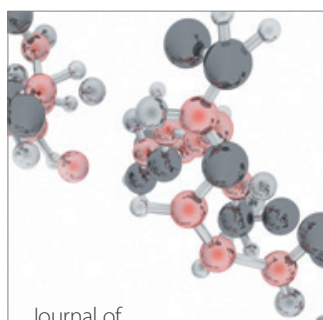

Analytical Methods

in Chemistry

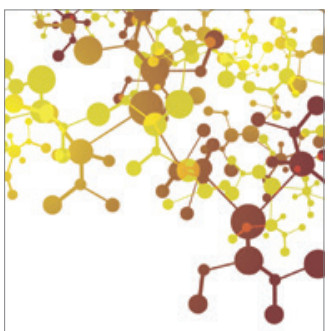

Journal of

Applied Chemistry

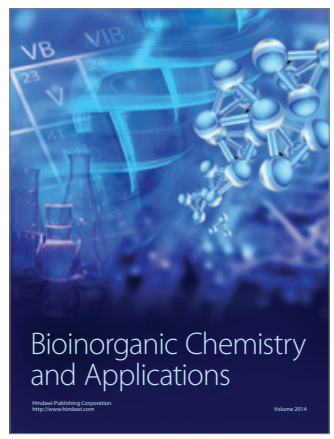

Inorganic Chemistry
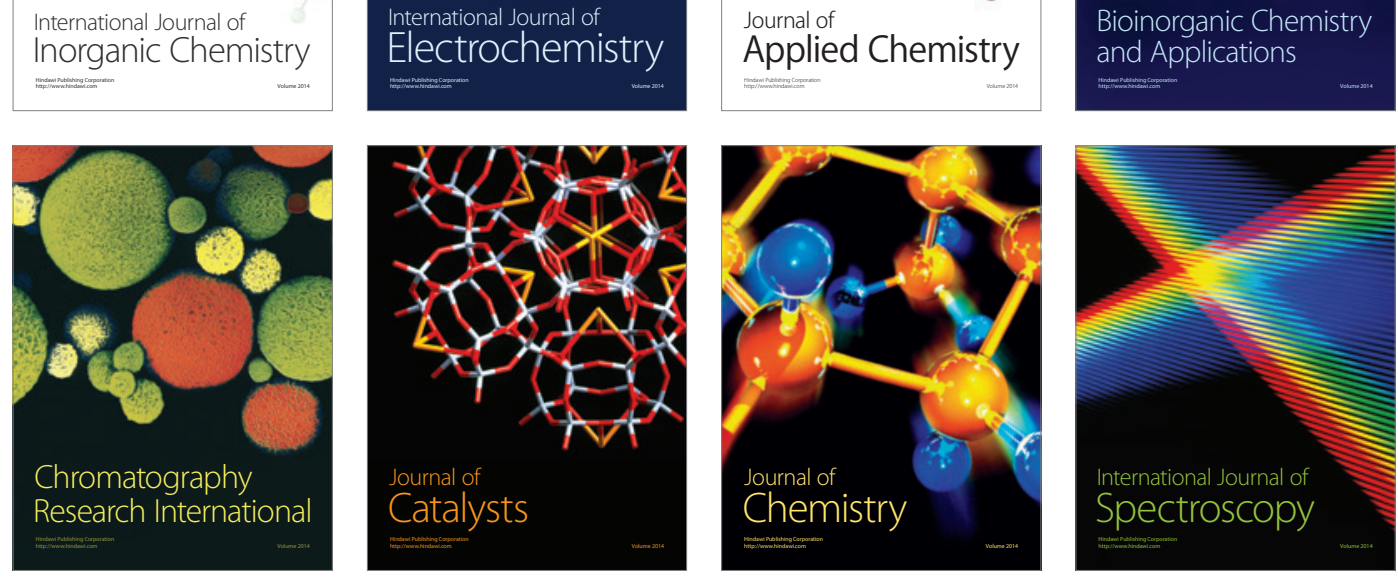